\title{
ASCENDING THE WASTE HIERARCHY: RE-USE POTENTIAL IN SWEDISH RECYCLING CENTRES
}

\section{Leonidas Milios * and Carl Dalhammar}

International Institute for Industrial Environmental Economics (IIIEE), Lund University, Tegnérsplatsen 4, 22350 Lund, Sweden
Article Info:
Received:
25 July 2019
Revised:
16 October 2019
Accepted:
31 October 2020
Available online:
5 March 2020
Keywords:
Waste hierarchy
Re-use
Recycling centre
Circular economy

\begin{abstract}
According to the waste hierarchy principle, which constitutes the basis of European waste legislation, waste prevention and re-use are considered - most of the times - better waste management options than recycling. However, prevention and re-use activities are difficult to operationalise and measure, without a monitoring framework in place. This contribution investigates the potential of re-using end-of-life products that have been disposed at recycling centres in Sweden. Recycling centres receive a wide variety of materials for recycling, of which a portion could be re-used instead. The aim is to identify what product groups can be re-used, the share of these potentially re-usable products in the recycling centres, and under what conditions their re-use is feasible. A literature review of similar studies, site visits at recycling centres in Sweden, and semi-structured interviews with relevant stakeholders were used to analyse the potential for re-use in private recycling centres in Sweden. The most suitable product groups for re-use identified are building materials, furniture and electrical equipment (mainly white goods), as other material types are mostly handled by charity organisations (e.g. textiles). There is significant potential for increasing re-use operations in recycling centres, but in order to be economically profitable it is important to identify the most suitable material fractions (or product groups) and engage in strategic partnerships that will allow more effective organisation of re-use processes.
\end{abstract}

\section{INTRODUCTION}

Waste management in the European Union (EU) is defined in the Waste Framework Directive (2008/98/EC), as amended by Directive (EU) 2018/851, which outlines the rules and conditions by which all waste management operations and planning is taking place in the EU Member States. It is complemented with a number of Directives setting the rules of managing separate waste streams (e.g. packaging waste, electronic waste etc.). The central principle of EU waste management, as it is expressed in Article 4 of the Waste Framework Directive, is the so-called "waste hierarchy". The waste hierarchy addresses the prioritisation of waste management options according to environmental and resource efficiency aspects. According to this hierarchy, waste management operations with negative environmental impacts are considered undesirable and should progressively be limited, and ultimately substituted by waste management operations that are considered more resource efficient and environmentally sound (European Commission, 2008).

The waste hierarchy includes the following waste management operations: (a) waste prevention; (b) re-use and preparation for re-use; (c) material and biological recycling; (d) energy recovery from waste; and (e) disposal to controlled or uncontrolled landfills, land or water. It is worth noting that although the hierarchy is addressing waste management, step (a) and partially step (b) of the hierarchy deal mainly with non-waste. Waste that is prevented is waste not generated, and re-use of a product means that the product did not become waste in the first place. However, step (b) might indicate that a product first became waste and then brought back to a suitable condition for reuse.

The term "re-use" is defined in the Waste Framework Directive as 'any operation by which products or components that are not waste are used again for the same purpose for which they were conceived.' (European Commission, 2008; Article 3). Product repair, refurbishment, and remanufacturing are all considered to be re-use operations (ljomah and Danis, 2012), and are often environmentally preferable to material recycling and manufacturing of new products as they save material resources and energy, reduce greenhouse gas emissions, and lead to safer handling of potential toxic substances in products (Sundin and Lee, 2012).

Waste management in the EU has moved steadily up- 
wards the waste hierarchy, prioritising options considered as best alternatives. Indeed, the recycling share of municipal solid waste has increased from 30\% in 2004 to nearly 44\% in 2014 (European Environment Agency, 2017). However, there is an apparent lack of information concerning the performance and progress of Member States in re-use operations. Considering that preparation for re-use is an immediate step up from recycling in the waste hierarchy, it would be evident for municipalities and regional authorities following waste legislation (and for their subcontracted private enterprises) to strive to get to the re-use stage of the waste hierarchy.

In Sweden, more than half of all municipal recycling centres include the possibility to receive materials for reuse, such as clothes and furniture, often in collaboration with charity organisations. There are also recycling centres with adjacent recycling parks that have extended operations, such as repairs and sales of second hand goods. The volume of waste submitted to the municipal recycling centres is steadily increasing, and so are the possibilities for re-use of a variety of products and materials (Avfall Sverige, 2018). Moreover, in addition to the municipal recycling centres, private enterprises have capabilities of collecting a variety of waste from municipal or private actors within their own facilities, with a good potential for re-use (STENA, 2016).

In this contribution, we are investigating the potential of re-use and the possibility of ascending the waste hierarchy in commercial recycling centres in Sweden. Similar to previous studies that have analysed the re-use potential in municipal recycling centres (Ljunggren Söderman et al., 2011; Hultén et al., 2018a; Hultén et al., 2018b), for this study we conducted a qualitative analysis of the different waste streams treated in two sorting facilities of the largest recycling operator in Sweden. The analysis aimed at assessing the type of waste streams and the quality of waste, and to examine if the waste could have been re-used instead of recycled. In this study, we did not consider the types of material such as plastic, metal or wood, but product groups such as furniture, building components, etc. Analysis of reuse potential at product level allows better understanding of where and when re-use is feasible, which could facilitate new business models for re-use involving the recycling centres (Zacho et al., 2018).

In the following sections, the main characteristics of re-use concerning environmental, economic and social aspects are presented, as well as the legal implications of re-use in Sweden. Also, previous experiences with re-use in municipal or private entities at various EU Member States are detailed to provide background context for our current study. Then, the methodological approach of this contribution is presented, followed by the integrated results and discussion. Finally, this contribution ends with presenting the main conclusions and future research opportunities.

\section{CHARACTERISTICS OF RE-USE}

This section outlines the sustainability characteristics of re-using end-of-life (EOL) products and presents the associated legal and organisational implications of re-use.
Additionally, previous studies on Swedish and other EU re-use centres are presented, highlighting important conditions of re-use relevant to the present study.

\subsection{Environmental benefits of re-use}

Waste prevention and re-use is generally considered a better environmental option than other treatments of waste. For instance, preventing the generation of one kilogramme of textile waste can potentially reduce carbon dioxide (CO2) emissions by $15 \mathrm{~kg}$, while the amount of reduced emissions is $8 \mathrm{~kg}$ of $\mathrm{CO} 2$ if that one $\mathrm{kg}$ of textiles is re-used and approximately $0-3 \mathrm{~kg}$ emissions reduction if textile waste is recycled (Avfall Sverige, 2015). A deviation from this general principle can occur when products have been designed to be much more energy-efficient in the use phase of their life-cycle. Generally, products that have a large energy consumption after manufacture are not favourable for re-use (Gutowski et al., 2011). Another example of products that are less suitable for re-use are products that contain hazardous substances which, when re-used, persist in the product stock in use and are not phased out (Eriksen et al., 2018).

A previous study by Ljunggren Söderman et al. (2011) measured the environmental impacts of re-use by life cycle assessment (LCA) methodology, using as case study the recycling centre Alelyckan situated in Gothenburg, Sweden. Contrary to a "traditional" recycling centre, where received waste are destined solely for recycling, the Alelyckan recycling centre offers the opportunity to collect waste for re-use before they reach the recycling bins. In 2010, the recycling centre prevented 358 tonnes of waste, which corresponds to 5.6 per cent of the total weighted waste received at the centre (Ljunggren Söderman et al., 2011). Figure 1 shows the amount of waste collected for re-use (tonnes) and the amounts that were actually re-used in each product category. The figure shows that the product groups with the largest amount re-used were textiles and metal products. Books were also commonly collected, but these proved difficult to re-use. Furthermore, the figure shows that all wood construction products collected were eventually re-used.

The study investigated, among other things, the environmental impacts (in the form of greenhouse gas emissions, acidification and eutrophication) due to avoiding new production and waste transport, and the increase or decrease in energy recovery (as in Sweden, most waste that is not re-used, composted or recycled is burned in municipal incinerators connected to district heating systems). The LCA calculations for the 358 tonnes of waste that could be reused confirmed that the greatest environmental benefit is due to replacement of new production. The carbon dioxide savings that could be made in one year by the introduction of Alelyckan, compared to a conventional recycling centre were, 1,300 tonnes of carbon dioxide equivalents (Ljunggren Söderman et al., 2011). This amount is equal to the total emissions of 120 Swedes over one year, including private and public consumption in and outside Sweden, i.e. about 11 tonnes per person per year (SEPA, 2018a). It is primarily textiles and small electric and electronic equipment (EEE) that have a major impact on avoided greenhouse gas emissions during re-use. For textiles, the result is largely 


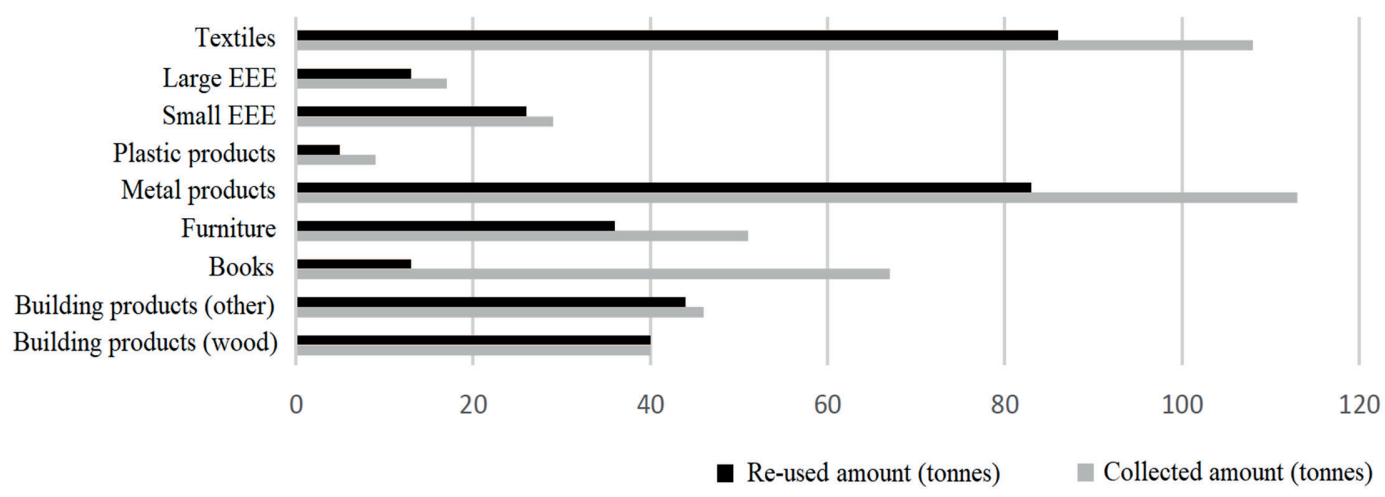

FIGURE 1: Collected and re-used amounts of waste at Alelyckan recycling centre in 2010 (Ljunggren Söderman et al., 2011). Note: EEE stands for Electric and Electronic Equipment.

influenced by the fact that large amounts of textiles were collected at the recycling centre, while small EEE have a greater environmental impact per tonne collected (Ljunggren Söderman et al., 2011).

The study also showed that in 2010 the recycling centre prevented emissions of substances with acidifying and eutrophication effect by 10 and 1.5 tonnes respectively, which is in the order of the annual emission of 400 Swedes. In conclusion, the study noted that if all recycling centres in Sweden were rebuilt with a re-use concept similar to Alelyckan, then about 80,000 tonnes of waste could be prevented annually (Ljunggren Söderman et al., 2011), which is as much waste generated as in a medium-sized Swedish city, taking into account that a Swede generates on average 473 $\mathrm{kg}$ of household waste per year (Avfall Sverige, 2018).

\subsection{Economic aspects of re-use}

The economics of a business, whether private, non-profit or public, plays a central role in determining its feasibility and long term sustainability. Unlike conventional recycling centres, the operating cost of a centre with a re-use focus is higher. Personnel costs increase as more staff is required to sort the incoming waste, inform visitors, and label waste that has been prepared for re-use. Higher premises costs arise as a result of an additional sorting station, storage facilities and more sorting containers (WSP, 2012). There are various alternatives to cover the increased costs. One example is to regulate the municipal waste tariff. This is possible since the preparation of waste for re-use can be classified as a recycling activity. There is therefore no legal obstacle to using income from the waste tariff to finance such activities (Avfall Sverige, 2014). In addition, it is commonly observed that re-use organisations in several EU countries have been receiving state support, directly or indirectly, to maintain their operations (Zajko and Hojnik, 2014).

Furthermore, the waste collected for re-use has an economic value as a product. It can therefore be assumed that re-use of products can also have higher economic benefits, in contrast to recycling (Avfall Sverige, 2015). The waste streams entering a recycling centre can be quite heterogeneous and can also vary depending on the season. This means that even the commercial value of the waste may vary, thus also the interest from external actors. The types of products received also affect the value of the waste. Products with a high commercial value will most probably not be left at a recycling centre (although this is not always the case). Products that end up in a recycling centre are most often things that households do not consider sufficiently valuable to divert in a second-hand market outlet. However, there is still some residual value in them, which can be harnessed if the recycling centre is connected to repair services (Hultén et al., 2018a).

\subsection{Social aspects of re-use}

The social effects of re-use concern mainly increased employment and inclusiveness. Traditionally, non-profit second-hand businesses provide a workplace opportunity for many people who find it difficult to enter the labour market in any other way. A study conducted to investigate social benefits related to second-hand activities (Jannesson and Nilsson, 2014) concluded that a large proportion (74\%) of people employed in a second-hand business, through an internship or work training (subsidised by public unemployment services), experienced increased meaningfulness, reduced stress, increased participation in society and improved social relations. There are also social effects for customers who buy second-hand products. A growing secondary market would have a positive effect on households as they gain greater access to affordable products. Other positive effects for the consumer may be the feeling of acting environmentally conscious or that the money from purchasing second-hand goes for a charitable purpose (Shaw and Williams, 2018).

\subsection{Legal aspects of re-use}

An important parameter when designing a re-use centre is the embedded legal framework concerning the management of waste and associated re-use activities. In Sweden, according to the Environmental Code (SFS 1998: 808), each municipality is responsible for disposing or recycling household waste. Part of the municipal responsibility is therefore to establish recycling centres where citizens can leave waste that are not collected from households. When a product has been submitted to a recycling centre, this is transferred to the municipality's ownership. The right of 
ownership means that the municipality has the exclusive right to decide on how the waste is to be treated, taking into account national guidelines such as the waste hierarchy (Avfall Sverige, 2014).

For businesses that handle products submitted with the explicit purpose of being re-used, and thus will not be classified as waste, a waste management permit does not have to be applied, according to the Environmental Assessment Ordinance (SEPA, 2017).

For re-use to be possible, in some cases it is required that the submitted waste is in some way processed or prepared for re-use. This may, for example, involve checking, repairing or cleaning. In the most recent amendment of the Environmental Assessment Ordinance (SFS 2013: 251), a point of appeal was added, namely para. 47 "Preparation for re-use" with business code 90.29. This facilitates the operations of businesses that work with preparation for re-use, as such activities are classified obligatory for notification and therefore do not have to undergo an authorization process, but only a notification to the municipality is required (SEPA, 2017).

An important aspect to take into account in municipal sales of recycled goods is the Competition Act (SFS 2008:579). This is because the state, county council and municipality must not conduct a sales activity that can distort or impede private competition. This may be the case if waste at a recycling centre is pre-treated and sold under municipal auspices. Other recycling operators do not have the same opportunity and can be disadvantaged. One possible interpretation, however, is that other actors are not able to run collection, sorting and preparation for re-use to the extent required to fulfil the municipal responsibility, and therefore there is no competitive advantage for the municipality. Regardless, the municipalities must take into account the Local Government Act (SFS 1991: 900) which states that a municipality must not conduct activities with a profit interest and that all activities within municipal operations must have a public interest purpose (Avfall Sverige, 2014).

To circumvent potential distortion in competition, and legally uncertain practices, municipalities could cooperate with private actors (Hultén et al., 2018a). The contractual form between a municipality and private actors affects the legal framework of the collaboration. The dividing line is defined by who pays and for what. Hultén et al. (2018a) provide several examples to illustrate such inconsistencies. For instance, if a municipality gives collected products to private operators, this can be seen as unauthorized individual support for traders. Transparent selection processes among players are needed and at least local rent or similar should be paid by the private parties. In another example, a municipality could pay private actors to receive collected products, and this could be considered as the provision of service to the municipality, and in that case formal public procurement processes must be applied. Finally, a municipality could sell collected products to private operators. Procurement or selection among relevant actors is not required formally if sales are made at market prices. On the other hand, if the sale is made by renting an area or at a discounted price, it may be an unauthorized individual support for the trader and the selection process becomes necessary.

\subsection{Re-use potential in municipal recycling centres in Sweden}

To identify the potential of re-use in a recycling centre, it is important to identify the type of products that are submitted and the condition they are in. A recent study conducted in two municipal recycling centres in Sweden (Norra Hamnen in Malmö and in Örkelljunga) quantified the received waste for re-use and assessed its quality and reuse potential (Hultén et al., 2018a; Hultén et al., 2018b). In total, 15.5 tonnes of waste was examined through composition analysis, and the re-use potential of nearly 17,000 products was assessed.

About a quarter of the waste examined was considered commercially or functionally re-usable (Figure 2). A very small percentage was judged to be commercially re-usable after repair (3\%), but many of the products that were considered to have a resale value in their existing condition would have a higher value if they were also repaired. Among all items deemed re-usable, a further distinction was made between commercially re-usable and functionally re-usable products. The latter, although retain functional capability (i.e. product can be used for its intended purpose), they have negligible economic value and are not commercially viable. That waste category constituted five percent by weight, including products such as used socks and plastic pots. More than two-thirds of the waste that was investigated consisted of other waste types such as packaging and garden waste or products in poor condition that could not been re-used.

The largest amount of commercially re-usable products did not belong to product groups traditionally handled by charity organizations, as for instance clothes. Building products, furniture, pallets and tools were commonly the ones that were identified with a high re-use potential. Repair work was not judged to be able to increase re-usable amounts to any notable extent, even if it was performed with no cost. Repair work could, however, increase the value of products already considered to be commercially re-usable. A simple cleaning would increase the value of the majority of products.

Hazardous substances were found in re-usable products, but not at alarming levels. Non-metallic toys and household utensils contained lead and nickel in 10 to 35 per cent of the products. Among toys and household utensils made of plastic or textile, bromine was detected in 20 and 25 per cent of products respectively. Laboratory tests revealed negligible levels of Polycyclic Aromatic Hydrocarbons (PAHs) and Perfluorinated Alkylated Substances (PFASs) in all samples. Phthalates were detected in half the samples but at levels below current legal limits. These findings cannot be used as general conclusions whether any specific kind of product should be re-used or not. The reason for this is that two very similar products may contain different levels of hazardous substances (Hultén et al., 2018a). 


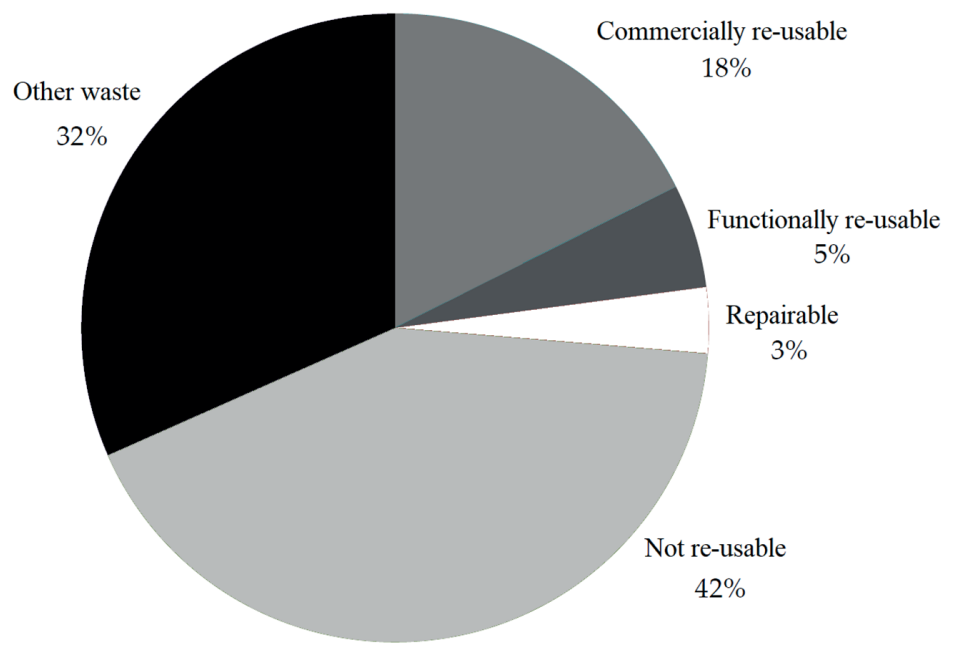

FIGURE 2: Results of the composition analysis of waste at two recycling centres (Norra Hamnen in Malmö and Örkelljunga), showing reuse potential expressed by weight of received waste (Hultén et al., 2018a).

\section{RE-USE EXPERIENCES IN EU MEMBER STATES}

Several re-use initiatives have sprung across the EU in recent years, with varying levels of success and organisational structures. In this section, following the detailed case study in Sweden (section 2.5), we present briefly a few initiatives that have provided increased re-use potential, as documented in literature. We take a closer look at the case of Flanders' KOMOSIE (Re-use network) and at reuse case studies in Austria, Denmark and Spain.

\subsection{Re-use network in Flanders}

The Flemish re-use network is represented by the non-profit organisation KOMOSIE, which stands for Federation of Environmental Entrepreneurs in the Social Economy. It is an umbrella organisation consisting of all re-use centres in Flanders, which have been accredited by the Public Waste Agency of Flanders (OVAM). The main pillars of success for the establishment of the re-use network in Flanders include: (1) the integration of re-use activities with the regional employment policy; (2) the close collaboration with municipalities by forming inter-municipal partnerships; (3) the pursuit of professionalization in operations and the constant monitoring and quality control; and (4) a carefully planned and communicated marketing policy, assisted by the support of the umbrella organisation KOMOSIE (Vandeputte et al., 2015).

By the beginning of the 1990s, the Flemish Waste Management Plan introduced the mandatory door-to-door collection of bulky household waste at least twice a year by municipalities, and the sorting of any recyclable materials. This requirement drove the municipalities to enact inter-municipal partnerships and to redesign their municipal solid waste policy. Re-use centres responded to this policy-driven opportunity by rapidly profiling themselves as an indispensable actor in the household waste collection and thus received a complementary role in the municipal waste policy (Vandeputte et al., 2015). Therefore, the Flemish re-use centres could sign agreements individually with
OVAM, and with this they would receive annual subsidy for four successive years, in line with the duration of the Waste Management Plan. To be eligible for this subsidy, the reuse centres were required to participate in supporting the Flemish prevention and recycling policy and to report annually their activities to OVAM. As a result, the re-use centres became strongly embedded within the Flemish waste policy and started to gain greater momentum (Vandeputte et al., 2015). Moreover, the re-use centres were integrated into the legal take-back obligation of waste electric and electronic equipment (WEEE), by the ordinance of the Flemish Government of 17 December 1997 on the establishment of the Flemish regulations regarding the prevention and management of waste (section 3.5 Brown and White goods Art. 3.5.2). With this decision, the collected amounts of WEEE by the Belgian Producer Responsibility Organisation (PRO) Recupel would be redirected first to re-use centres for potential re-use and preparation for re-use, before reaching the subsequent recycling stage within the waste hierarchy policy framework (Vandeputte et al., 2015).

The professionalization of the re-use centres was an important step to consolidate the position achieved within the waste policy. To increase the profile of re-use centres and raise the confidence and sales of re-used products, it was necessary to develop a strong brand with a far-reaching communication strategy. Moreover, to boost confidence and quality in their products, re-use shops associated with the network (De Kringwinkel shops) introduced periodic external auditing that ensured a set of quality standards, in line with international practice (Vandeputte et al., 2015). The re-use network went even a step further, by introducing their own quality label for re-used goods named "Revisie", mostly in relation to re-used electrical equipment. The "Revisie" quality label reassured the customers that an electric device from the re-use shop (De Kringwinkel) would work properly and safely. Every device was subjected to thorough technical inspections, and if needed it would be professionally repaired and tested (Gåvertsson et al., 2018).

Profit generation is not a goal in itself for the re-use 
shops, but healthy financial performance is a necessary condition for sustainable operations and employment opportunities. Re-use shops that mainly rely on subsidies or on the goodwill of volunteers for daily operations cannot lead sustainable business (Vandeputte et al., 2015). The total turnover of re-use centres in Flanders is made up from two main sources, namely the shop-generated sales and the subsidies. Shop revenue is generated from the sale of re-used goods, which constituted $39 \%$ of the revenue in 2014. Other revenues are generated from the sale of materials to the recycling sector and tonnage fees for the collection ( $14 \%$ of the total revenue). The rest and most important share of the revenues was attributed to subsidies, mostly given for employment (Vandeputte et al., 2015).

There are 31 re-use centres in Flanders which are categorised by OVAM in 2 groups, the centres that operate on a broader scope (22) and the traditional ones (9). Traditional re-use centres collect only EOL products that have a re-use potential (not waste), while the broader scope centres have the possibility to collect larger amount of bulky waste (including also non-reusable items). Of the total quantity of collected products, approximately half of the goods redirected for re-use in 2014 were furniture and textiles, both in quantity $(\mathrm{kg})$ and value (EUR). In the case of WEEE, just $12 \%$ of the collected amount was re-used, while the rest was diverted to recycling. Only one out of four books and multimedia (record vinyls, compact discs, etc.) could be reused through the re-use shops in Flanders. Approximately $55 \%$ of the total goods inflow was non-reusable (Vandeputte et al., 2015).

\subsection{Re-use case studies in Denmark and Spain}

There are very few case studies in scientific literature investigating the potential for re-use in recycling centres and/or through separate collection of reusable EOL items. One case study refers to a project in a municipal waste management company in Northern Denmark (Zacho et al., 2018) and another study analyses the findings of a pilot study of separate collection for re-use in Spain (Bovea et al., 2016).

In the case of the municipal waste company in Denmark, the revised configuration of the regional recycling centre included a re-use shop with a workshop where the preparation for re-use processes were conducted, employing nine contracted full-time employees and six employees on special conditions who might otherwise have been outside the labour market. The latter have been employed through collaboration with the municipality's employment office and they had a mentor in their job training (Zacho et al., 2018).

After the introduction of the re-use centre, the amount of reusable items that were collected out of the combustible waste stream doubled and reached $3.23 \%$ of the total in 2016. The labour and logistical input to the process of sorting out and processing EOL products for re-use was so costly that the revenues from the sales of re-used products just covered the expenses. This means that the value of items for re-use at the recycling centre do not result in economic profits, but the benefits are mostly concentrated in the local employment opportunities that re-use provides.
The economic value of EOL products is at the lowest point at the stage of collection. If the preparation processes result to a deficit, the expenses will ultimately be charged to the citizens that are serviced by the municipal waste organisation (Zacho et al., 2018).

Bovea et al. (2016) proposed a general methodology for assessing the potential re-use of small WEEE, focusing on devices classified as household appliances. The study presented a first approach to the "preparation for re-use" strategy that the EU WEEE Directive (2012/19/EU) advocates. The case study covered a selective collection campaign of small household WEEE in Castellon de la Plana (Spain) from March to June 2015. The campaign was carried out in collaboration with a social enterprise which was authorised for the management of WEEE. The collection points were located in different educational centres located across the town. After assessing a sample of $87.7 \mathrm{~kg}$ (96 units) from the collected small household WEEE, it was calculated that $30.2 \%$ of that sample were redirected to recycling, $67.7 \%$ had a potential for re-use, and $2.1 \%$ could be re-used directly (Bovea et al., 2016).

\subsection{Re-use operations in Austria}

Austria has a well organised waste system that enables the collection of bulky waste from households, including bulky waste wood, household scrap metal (excluding packaging) and WEEE among others. In 2010, it was reported that 601,700 tonnes of re-usable items have been collected in Austria, which means approximately $72 \mathrm{~kg}$ per capita of formally collected bulky waste (BMLFUW, 2010). On top of that, Ramusch et al. (2015) investigated that additionally up to a further $12 \mathrm{~kg}$ per capita might have ended up as waste taken care of by the informal or second-hand sector, which exported them for re-use in nearby countries. This resulted to an estimation of approximately 100,000 tonnes of additional reusable items informally collected in Austria.

A widely publicised example of re-use in Austria refers to the Repair- and Service Center R.U.S.Z (Reparatur- und Servicezentrum R.U.S.Z) in Vienna. Founded in 1998 as a non-profit organisation, the centre pursues economical, environmental, and social outcomes, as documented by the recovery and repairing of about 8,000 used products per year, and the reintegration of long-term unemployed persons (Lechner and Reimann, 2015).

R.U.S.Z receives used products from different sources. The main ways to collect products is either through direct delivery to the store by the customer, or through a collection service at the customer's home. Acquisition quantities coming from both sources of supply can be actively influenced by a fee for the pick-up service or by efforts for advertisement and information. More than half of product acquisitions is through delivery by customers to the shop. Since 2012, R.U.S.Z charged a fee of EUR 9 for the pick-up service, compared with EUR 24 in the year 2011. The price reduction was due to the public support of the municipality of Vienna which subsidised the pickup service (Lechner and Reimann, 2015).

All products that are processed in R.U.S.Z can be sold relatively easy, as the demand is - on average - greater than the number of processed items. Finished re-used 
goods are not always sold instantly but there is a certain delay between the end of processing and the actual sale, so the time when a product is finished may not necessarily coincide with the demand for a product. Regarding the sale prices of re-used goods, a rule of thumb by R.U.S.Z is to charge one third of the price of a new product for the equivalent re-used one. In case of high quality refurbished products, in an "as-new" condition and those associated with a prestigious brand image, the sale price can be up to half of the price of a new product. Moreover, following legal requirements, R.U.S.Z can also offer a guarantee of one year for repaired products (Lechner and Reimann, 2015).

R.U.S.Z has been supported widely by recurring media campaigns, assisted by the municipality of Vienna. However, this case study also indicated that there was a lack of collaboration between manufacturers, retailers, and the re-use sector, despite the fact that national and regional legislation aimed at boosting preparation for re-use according to EU Directives. Large retailers in Austria take back customers' used white goods when selling a new one but they are not willing to cooperate with the R.U.S.Z by providing the collected items, as they fear that the re-used white goods could affect the volume of their own sales. According to R.U.S.Z, the retailers' superior market position in collecting used items was one of the main reasons for low supply of used products at the re-use centre (Lechner and Reimann, 2015).

In a study concerning the replacement, repair and reuse of mobile phones in Austria (Wieser and Tröger, 2018), a different perspective is presented on why supply of used goods might be shrinking. Austrian consumers are generally avoiding to dispose of their old phones. The authors suggest that offering warranties for used phones may be the most effective way for establishing a viable domestic re-use market. A functioning repair system and ease of disassembly of EOL products are essential components for a sustainable re-use sector. However, it is observed that users do not repair broken mobile phones, partly due to the high cost associated with repairs. Therefore, a combination of tax cuts for repair services and more information about the reparability of mobiles could encourage people to repair defective devices (Wieser and Tröger, 2018).

\section{METHOD}

A qualitative analysis of the different waste streams in two sorting facilities of the largest private recycling operator in Sweden was conducted for this study. The analysis aimed at assessing the type of waste streams and the quality of waste, to examine if the waste could have been re-used instead of recycled, and to assess the potential for re-use of the identified waste streams. The approach in this contribution followed previous studies on the analysis of re-use potential in municipal recycling centres in Sweden (Ljunggren Söderman et al., 2011; Hultén et al., 2018a; Hultén et al., 2018b) and Denmark (Zacho et al., 2018), however, without quantitatively analysing the samples due to confidentiality issues (business competition).

The scope of the study derives from the strategic ambition of Sweden to transition to a resource efficient low carbon economy and to sustain growth and jobs. In this effort all economic actors have particularly important roles to play, and besides the public waste management authorities a number of private actors are actively involved in recycling and re-use operations. Specifically, as the resource efficiency agenda is advancing within a circular economy paradigm, more and more private enterprises are requesting re-use solutions for their discarded equipment. Therefore, private actors primarily active in recycling so far, have been particularly keen to explore new ways to increase the re-use potential of EOL equipment.

To collect empirical evidence on the potential of re-use, on-site field investigations were conducted in two recycling centres of the largest private recycler company in Sweden (henceforth Recycling company A). The visits were complemented by ten interviews with relevant stakeholders in the recycling and re-use sector in Sweden, both public and private. The majority of stakeholders interviewed were connected to the Recycling company $\mathrm{A}$, holding various positions, from branch manager to research and development coordinator. Further interviewees were identified through non-probability sampling method (Bryman, 2016), following suggestions or direct collaborating stakeholders of the company. The full list of interviewees is presented in Table 1. The examined recycling centres are located in Malmö and Kristianstad, both in the Scania region of South Sweden.

TABLE 1: List of interviews.

\begin{tabular}{|c|c|c|c|c|}
\hline$\#$ & Stakeholder type & Interviewee role & Sector & Type \\
\hline 1 & Recycling company A & Head of sustainability & Recycling & Private \\
\hline 2 & Recycling company A & Branch manager (Stockholm) & Recycling & Private \\
\hline 3 & Recycling company A & Branch Manager (Malmö) & Recycling & Private \\
\hline 4 & Recycling company A & R\&D project manager & Recycling & Private \\
\hline 5 & Recycling company A & Branch manager (Kristianstad) & Recycling & Private \\
\hline 6 & Recycling company A & Branch manager (Linköping) & Recycling & Private \\
\hline 7 & EEE producer responsibility organisation (PRO) & Vice CEO - Business development & Recycling / Re-use & Private \\
\hline 8 & Re-use municipal company & Work supervisor & Re-use & Public \\
\hline 9 & Re-use municipal department & Project manager & Re-use & Public \\
\hline 10 & Re-use company & Marketing director & Re-use & Private \\
\hline
\end{tabular}


The design of the semi-structured interviews purposefully included open-ended questions in order to capture the diversity of opinion among the different stakeholders in the company and the associated stakeholders outside the company. Although semi-structured interviews are sometimes criticized for lack of generalizability, they are beneficial at providing in-depth exploration of the subject of interest and for seeking new insights (Bryman, 2016). Individual interview guides were used, as the interviewees are engaged in different departments and positions in relation to potential re-use operations, both internally and externally. Due to geographic disparity of the interviewed stakeholders, the majority of interviews were conducted by telephone.

\section{RESULTS AND DISCUSSION}

\subsection{Site visits at two recycling centres in South Sweden (Scania)}

For the purposes of this study, two recycling centres belonging to the largest recycling company in Sweden were visited (in Malmö and Kristianstad), and their organisation and operations is presented in this section. The recycling centre in Malmö mainly handles iron, other non-ferrous metals, hazardous waste, electronics, paper and plastic. It also handles a small portion of wood waste and rubber. Waste is transported to the Malmö recycling centre from a variety of client companies, but also from other recycling centres across the country that belong to Recycling company A. Iron, aluminium and other metals are treated by cutting and packaging into smaller parts for shipping to smelting facilities in Sweden and abroad. Also hazardous waste, electronics, paper and plastic are sent on to other recycling facilities. So, the recycling centre acts solely as a sorting and logistics facility, while the actual recycling of materials happens elsewhere.

The recycling centre in Kristianstad differs from the company's other facilities, as it includes a municipal recycling centre within its premises. Private persons come to the recycling centre, as well as companies to dispose waste for recycling. The centre handles about 70,000 tonnes material per year, focusing on so-called alternative raw materials such as building materials, pressure-impregnated wood and garden waste. Building materials are recycled and pressure-treated wood is treated as hazardous waste. The garden waste is crushed and sieved and then composted to soil or turned to biofuel for heating plants. The recycling centre receives also EEE waste, which is then forwarded to the company's major recycling facility in Halmstad.

This recycling centre is collaborating with the social services of Kristianstad municipality, which drives a second-hand store in connection to the recycling centre. There, individuals can leave everything from electronics, furniture and household items to clothes, toys and books. Individuals have the option to dispose items and materials in a container for re-use in close proximity to containers for recycling. The items left for re-use are sorted and repaired if necessary, and then the items go on for sale in the store. Cooperation with the social services means that people with special needs and people in training can receive em- ployment, which contributes to the social aspect of sustainability. The staff working there has shown great appreciation for this collaboration, and the job promotes their creative and social development. The second-hand store, which has a large number of visitors, has also become popular among the inhabitants of the municipality and in the rest of Scania region.

\subsection{Analysis of interviews}

Through the interviews with key staff of Recycling company $A$ and other relevant external stakeholders, a number of common obstacles for re-use were identified, largely consistent with what has been mentioned in literature. Due to the current legal framework, re-use of certain products is not possible. When a product is classified as waste, it is not allowed to be removed from the receiving waste facility and thus not allowed to be re-used. However, it is possible to bring waste under the condition "preparation for re-use" which would allow a product to become re-usable under certain conditions, fulfilling a number of criteria according to EU Waste Directives. The classification of EOL products as waste can be avoided by introducing separate collection of the incoming items into reusable fractions - meaning they are not waste- as in the case of Swedish recycling centres with an embedded re-use section and the collection services of re-use centres in Flanders and Vienna.

A product's design can make re-use more difficult, especially if it is difficult to dismantle and repair the product (Vanegas et al., 2018). Transport and logistics can also prevent re-use. Many products are damaged during transportation (Cole et al., 2018). For these products it is difficult to estimate any potential for re-use as they are not intact upon arrival at the recycling centre, and effective re-use practices require upstream measures. This is especially true for white goods. Further, for re-use to be economically feasible and profitable there needs to be a certain volume of a specific product (or product group) and an efficient process to prepare it for re-use. Previous experiences with re-use of ad-hoc collected products that do not form economies of scale, as in the case of the municipal recycling centre in Denmark, showed that re-use is not profitable but can marginally cover the costs of preparation for re-use (Zacho et al., 2018).

Additionally, peoples' attitude to re-used products is considered a significant obstacle. Private individuals may be negatively inclined to re-use due to lack of information about the product and its functionality, or its potential hazardousness (Ylä-Mella et al., 2015). Moreover, it is quite common that people would throw away functional products due to the desire to upgrade their products and acquire the latest version available on the market, although this is not always the case as Wieser and Tröger (2018) illustrated in a case of mobile phones re-use in Austria.

An overarching obstacle to re-use is the additional workload and time it would take to prepare a product for reuse. The product must be sorted out, checked, cleaned, repaired (if needed), quality assured, transported and finally sold to a customer. The potential product opportunities for re-use identified through the interviews include: 1 ) building materials, 2) furniture, and 3) consumer electronics. There 
is potential to re-use whole white goods, or components in white goods, but this must be done upstream before the goods arrive at the company's premises. Ultimately, the potential for re-use is largely influenced by the type of facility, as it is common that different facilities receive and handle different types of waste.

For materials such as bricks and tiles, there are clear incentives for re-use instead for recycling. This is because the former leads to significantly reduced environmental impacts compared to the latter (Nußholz et al., 2019). Moreover, these materials are relatively more expensive compared to other building materials such as wood and plaster. Increased re-use of construction and demolition waste could be achieved in different ways, for instance through material exchanges linked to either construction and demolition companies or recycling companies. There are several existing platforms that offer such services, which are mainly independent initiatives not being part of construction and demolition companies or conventional recycling companies. Furthermore, focus should be placed on demolition practices that favour separate collection of building components such as windows and doors, which will effectively increase their re-use potential. However, this can be a costly endeavour that might not be feasible by just one recycling company. Policy support in this area could incentivise the uptake of more selective demolition in the future. Differentiated fees between sorted and unsorted construction and demolition waste disposal could rationalise and balance the higher cost of selective demolition, which today directs demolition actors to prefer conventional demolition practices. Sales of re-used building materials could become a part of the recycling company's business model, for example by cooperating with actors already active in this area (e.g. Malmö Återbyggdepå).

In the case of re-using furniture, transport and warehousing can be complicated and costly, and these consist major obstacles in re-use potential (Öhgren et al., 2019). Transportation and storage of furniture for re-use requires more space and needs to be handled more carefully than material just for recycling. Local solutions for the sale of re-used furniture is an environment-friendly and cost-effective alternative, compared to a national scheme where the furniture must be transported longer distances. This point was also illustrated in the case of the re-use centre in Vienna, where finished products for re-use would be redirected back to the market in irregular time intervals and be able to cover the local demand of the citizens of Vienna (Lechner and Reimann, 2015). A large amount of office furniture with high potential for re-use usually becomes available when companies relocate or restructure. Through collaboration with other actors, Recycling company A can find opportunities for re-using such furniture before they arrive at the recycling centres, thus avoiding the large and costly transportation to and from the recycling centres. Then, there is potential to cooperate with, for example, moving companies which also transport furniture in a safer manner, avoiding damage of the product. Consumers' preference to divert old furniture for re-use is relatively high, and being offered an easy way to dispose old furniture is considered of great importance.
A major obstacle to the re-use of EEE is the desire of consumers to buy new products instead of used (Ylä-Mella et al., 2015). Newly manufactured products can be relatively inexpensive, which makes it economically accessible (Watson et al., 2017). In order to be able to increase the re-use of EEE, it is important to have secure handling already from the collection stage, as these products can be damaged easily if not handled properly. The case study of selective collection of small household WEEE proves this point and indicates that the re-use potential can be up to $70 \%$ of the collected WEEE (Bovea et al., 2016). When WEEE arrive in the recycling centres, it is usually too late to restore or dismantle them, as it is often not economically desirable. In addition, there is uncertainty about the products' performance and safety. Used EEE may have been disposed due to electrical faults, which can lead to fire risk and danger for further use. One incentive for re-using electronics is to provide a warranty or quality label on the re-used product (Gåvertsson et al., 2018). In this way, the customer can feel safe because the product is guaranteed to work properly for a certain period of time after the purchase. This is something that companies working exclusively with re-use (repair and remanufacturing services, as in the case of R.U.S.Z in Vienna) can readily offer, but it might be more difficult for a recycling company to provide - let alone costly. However, there is still potential for salvaging components of damaged EEE that are still operational and can find a second life as spare parts on the market, provided prices can match the costs of operations (dismantling, cleaning and forwarding to the market) performed by the recycling company.

\subsection{Actions for increasing re-use in private recy- cling centres}

Recycling company A, the subject of analysis in this contribution, would firstly need to focus on re-use opportunities from waste received directly through industrial partners rather than what comes from its recycling centres, which usually exhibit unpredictable and heterogeneous waste flows. Thus, it can reap the readily available opportunities and work with customers to develop business agreements that favour re-use, already before the collection of EOL products. Materials sorted out for re-use from private individuals and other customers at recycling centres are of varying quality and often require further processing, which is labour intensive.

Additionally, Recycling company A could focus on products identified in its recycling centres by this study, including bricks and tiles, furniture and white goods, to the extent possible. EEE in the company's recycling centres are difficult to re-use, however, there is some potential for white goods. Cooperation with other companies is seen as a key action, for example with other private re-use and second-hand sales enterprises or the Swedish EEE Producer Responsibility Organisation (PRO) 'El-Kretsen', to enable the re-use of white goods. Establishing an on-line platform for sales of white goods is a step in the right direction. The most important issue about both furniture and EEE is that the handling of the products is done carefully. 
It can be problematic for a recycling company to handle at the same time sales, repair and storage of products and materials for re-use, as it is not included in the company's current business model. However, Recycling company A could act as an intermediary in the re-use process, by sorting out the products and materials that could be re-used and forward them to other actors who are responsible for repair and sales of second-hand goods. This requires further development of the current business model of the company and its logistics solutions. Moreover, collaboration with diverse actors is required, while also finding mutual profitability within the network and the re-use process. One barrier is that it requires time and resources to develop new business models, therefore investments must be able to be repaid through the re-use process. The operations may initially run at a loss until more efficient processes and larger volumes are established. Another difficulty is that the process involves many steps and actors with different costs for both work and transport. The profit margin can therefore be small, if there is not high enough value remaining in the products at the secondary market. Some products received at recycling centres may have a low purchase price and therefore reflect a low value in the secondary market. So, it is not economically viable to repair and sell these products. Interestingly, our interview with the PRO revealed that in the case of white goods there may be more value in single components than in the entire product. This is due to the fact that the breakdown of a white good tends to be caused by single components. Access to components can therefore support repair activities, as newly manufactured spare parts tend to be expensive.

Special potential for re-use is available for materials that appear in large volumes, as this means a more predictable flow that can be managed more effectively. Company executives in the recycling sector generally believe that re-use can become profitable in the future, but changes in society's attitude to re-used products is required, as well as policies that make re-use more attractive. Ultimately, in line with increased environmental public awareness, re-use of products will increase in the future, which means a reduction of material flows to recycling companies. For this reason it is imperative to take advantage of the business opportunities that exist within re-use, or else run the risk of lower revenues in the future.

\section{CONCLUSIONS}

Within a circular economy paradigm, EU Member States strive to ascend the 'waste hierarchy' and retain materials and energy in the economy by re-using products as much as possible. Many EU members have achieved relatively high recycling rates but the next challenge in waste management is how to prevent waste, including promoting reuse of EOL products.

This contribution presented a comprehensive approach in the development of re-use operations at recycling centres in Sweden and potentially internationally. It showed that there is a great potential to collect and re-use more products that currently are only recycled. The potential for increased re-use is demonstrated both in municipal recycling centres (public), by analysing previous studies, but also in private recycling centres operated by large recycling companies in Sweden. Achieving higher re-use rates is not only a public responsibility, but private enterprises have also a critical role to play. Therefore, the focus in this study was on the private sector and on how a "traditional" recycling company can find opportunities to adopt a more circular business model and include re-use in its operations.

About a quarter of the total waste collected in recycling centres can be commercially or at least functionally re-used, resulting in significant environmental and social gains with inconclusive economic benefits. Product groups with the highest re-use potential in private recycling centres are building materials, furniture and EEE. However, taping on this potential, private enterprises are required to explore new types of collaborations both with other private actors and public authorities. Increased collaboration and prioritisation of suitable product groups and market opportunities could effectively increase re-use in the future and mitigate potential risks of reduced recycling business activities, due to waste prevention and re-use upscaling.

Consequently, a more integrated investigation would be beneficial to determine the conditions of such collaborative actions. Therefore, future research could expand on this study by quantifying the flows of re-usable products in more recycling centres (both public and private) and map out the re-use dynamics at a regional or even national scale. Furthermore, a wider market investigation in the potential market demand and supply of re-used equipment both domestically and internationally could enable a more comprehensive economic analysis.

\section{ACKNOWLEDGMENTS}

This research was supported by the Mistra REES (Resource Efficient and Effective Solutions) programme, funded by Mistra (The Swedish Foundation for Strategic Environmental Research). Furthermore, we acknowledge the contribution of Cecilia Bengtsson, Emelie Wihlborg, Emma Sjögren, Fritiof Pröjts Erlandsson, Jonas Hägg, Karoline Johansson, Maja Dahlbom, Maria Schönning and Martin Karlberg for conducting interviews with relevant stakeholders.

\section{REFERENCES}

Avfall Sverige. (2014). Juridiska förutsättningar för förebyggande och återanvändning. Malmö, Sweden: Avfall Sverige.

Avfall Sverige. (2015). Goda exempel på avfallsförebyggande. Retrieved from https://www.avfallsverige.se/fileadmin/user_upload/ Publikationer/2015-03.pdf [accessed 30.04.2019].

Avfall Sverige. (2018). Swedish waste management 2018. Retrieved from https://www.avfallsverige.se/fileadmin/user_upload/Publikationer/Avfallshantering_2018_EN.pdf [accessed 30.04.2019]

BMLFUW (2010). Federal Waste Management Plan 2011. Bundesministerium für Land- und Forstwirtschaft, Umwelt und Wasserwirtschaft, Vienna.

Bovea, M. D., Ibáñez-Forés, V., Pérez-Belis, V., \& Quemades-Beltrán, P. (2016). Potential reuse of small household waste electrical and electronic equipment: Methodology and case study. Waste Management, 53, 204-2017. DOI: 10.1016/j.wasman.2016.03.038.

Bryman, A. (2016). Social Research Methods (5th ed.). Oxford: Oxford University Press. 
Cole, C., Gnanapragasam, A., Singh, J., \& Cooper, T. (2018). Enhancing Reuse and Resource Recovery of Electrical and Electronic Equipment with Reverse Logistics to Meet Carbon Reduction Targets. Procedia CIRP, 69, 980-985. DOI: 10.1016/j. procir.2017.11.019.

European Environment Agency. (2017). Waste recycling indicator assessment. Retrieved from https://www.eea.europa.eu/dataand-maps/indicators/waste-recycling-1/assessment [accessed 30.04.2019].

Eriksen, M. P., Damgaard, A., Boldrin, A., \& Astrup, T. F. (2018). Quality Assessment and Circularity Potential of Recovery Systems for Household Plastic Waste. Journal of Industrial Ecology, 23(1), 156168. DOI: $10.1111 /$ jiec. 12822.

European Commission. (2018). Directive 2008/98/EC of the European Parliament and of the Council of 19 November 2008 on waste and repealing certain Directives. Retrieved from https://eur-lex.europa.eu/legal-content/EN/TXT/?uri=CELEX:32008L0098 [accessed 30.04.2019]

Gåvertsson, I., Milios, L., \& Dalhammar, C. (2018). Quality Labelling for Re-used ICT Equipment to Support Consumer Choice in the Circular Economy. Journal of Consumer Policy. DOI: 10.1007/s10603018-9397-9.

Gutowski, T. G., Sahni, S., Boustani, A., \& Graves, S. C. (2011). Remanufacturing and Energy Savings. Environmental Science \& Technology, 45(10), 4540-4547. DOI: 10.1021/es102598b.

Hultén, J., Youhanan, L., \& Sandkvist, F. (2018a). Ökad återanvändning genom ökad samordning: Förstudie om en Återbrukshubb. Retrieved from https://urbanmagma.se/wordpress/wp-content/ uploads/2018/06/\%C3\%85terbrukshubb-IVL-f\%C3\%B6rstudie-rapport-201801.pdf [accessed 30.04.2019].

Hultén, J., Youhanan, L., Sandkvist, F., Fång, J., Belleza, E., \& Vukicevic, S. (2018b). Potential för ökad återanvändning - fallstudie återvinningscentraler. Retrieved from https://www.ivl.se/download/18.72aeb1b0166c003cd0d1b86/1542726511574/B2316. pdf [accessed 30.04.2019].

ljomah, W., \& Danis, M. (2012). Refurbishment and reuse of WEEE. In V. Goodship \& A. Stevels (Eds.), Waste electrical and electronic equipment (WEEE) handbook ( $p$ 145). Cambridge, UK: Woodhead Publishing.

Jannesson, E., \& Nilsson, E. (2014). En prognostiserande SROI-analys av Ideell Second Hand. Retrieved from http://www.sofisam.se/ download/18.727874b114bb71d3df1ba2c5/1472023479950 [accessed 30.04.2019]

Lechner, G., \& Reimann, M. (2015). Reprocessing and repairing white and brown goods - the R.U.S.Z case: an independent and non-profit business. Journal of Remanufacturing, 5, 3. DOI: 10.1186/s13243015-0012-9.

Ljunggren Söderman, M., Palm, D., \& Rydberg, T. (2011). Förebygga avfall med kretsloppsparker: Analys av miljöpåverkan. Retrieved from https://www.ivl.se/download/18.343dc99d14e8bb0f58b75e0/1463409433760/B1958.pdf [accessed 30.04.2019].

Nußholz, J. L. K., Rasmussen, F. N., \& Milios, L. (2019). Circular Building Materials: Carbon savings potential and the role of business model innovation and public policy. Resources, Conservation and Recycling, 141, 308-316. DOI: 10.1016/j.resconrec.2018.10.036.

Öhgren, M., Milios, L., Dalhammar, C., Lindahl, M., 2019. Public procurement of remanufactured furniture and the potential for procuring product-service systems (PSS) solutions. Procedia CIRP, 83, 151156. DOI:10.1016/j.procir.2019.02.134
Ramusch, R., Pertl, A., Scherhaufer, S., Schmied, E., \& Obersteiner, G. (2015). Modelling informally collected quantities of bulky waste and reusable items in Austria. Waste Management, 44, 3-14. DOI: 10.1016/j.wasman.2015.07.015.

SEPA. (2017). Vägledning till MPF 29 kap. Avfall. Retrieved from https://www.naturvardsverket.se/upload/stod-i-miljoarbetet/vagledning/miljoprovning/29-kap-avfall-vagledning.pdf [accessed 30.04.2019].

SEPA. (2018). Konsumtionsbaserade växthusgasutsläpp per person och år. Retrieved from https://www.naturvardsverket.se/Sa-marmiljon/Statistik-A-O/Vaxthusgaser-konsumtionsbaserade-utslapp-per-person/ [accessed 30.04.2019].

Shaw, P., \& Williams, I. (2018). Reuse in practice: The UK's car and clothing sectors. Detritus, 4, 36-47. DOI: 10.31025/26114135/2018.13735

STENA. (2016). Sustainability Report 2016. Retrieved from https:// www.stenarecycling.se/contentassets/e3892f8740494cbcacd79c9490a189fd/hallbarhetsredovisning_2016_eng.pdf [accessed 30.04.2019].

Sundin, E., \& Lee, H. M. (2012). In what way is remanufacturing good for the environment? In M. Matsumoto, Y. Umeda, K. Masui, \& S. Fukushige (Eds.), Design for innovative value towards a sustainable society: Proceedings of EcoDesign 2011: 7th International Symposium on Environmentally Conscious Design and Inverse Manufacturing (pp. 552-557). Dordrecht, Netherlands: Springer.

Vandeputte, A., Lemahieu, V., Van Rumst, T., Pauwels, H., Wagendorp, T., Poelmans, E., Blondeel, J., \& Willem, M. (2015). How to start a Re-use Shop? An overview of more than two decades of re-use in Flanders. Retrieved from https://www.ovam.be/sites/default/files/atoms/ files/2015_Folder-Kringloop-engels_LR.pdf [accessed 10.10.2019].

Vanegas, P., Peeters, J. R., Cattrysse, D., Tecchio, P., Ardente, F., Mathieux, F., Dewulf, W., \& Duflou, J. R. (2018). Ease of disassembly of products to support circular economy strategies. Resources, Conservation and Recycling, 135, 323-334. DOI: 10.1016/j.resconrec.2017.06.022

Watson, D., Gylling, A. C., Tojo, N., Throne-Holst, H., Bauer, B., \& Milios, L. (2017). Circular Business Models in the Mobile Phone Industry. Copenhagen, Denmark: Nordic Council of Ministers. DOI: 10.6027/ TN2017-560.

Wieser, H., \& Tröger, N. (2018). Exploring the inner loops of the circular economy: Replacement, repair, and reuse of mobile phones in Austria. Journal of Cleaner Production, 172, 3042-3055. DOI: 10.1016/j.jclepro.2017.11.106

WSP. (2012). Förslag till ändring av miljöbalken: Konsekvensanalys av tydligare kommunalt ansvar för återanvändning av hushållsavfall. Retrieved from https://sverigesradio.se/diverse/appdata/isidor/ files/3345/12115.pdf [accessed 30.04.2019]

Ylä-Mella, J., Keiski, R. L., \& Pongrácz, E. (2015). Electronic waste recovery in Finland: Consumers' perceptions towards recycling and re-use of mobile phones. Waste Management, 45, 374-384. DOI: 10.1016/j.wasman.2015.02.031.

Zacho, K. O., Mosgaard, M., \& Riisgaard, H. (2018). Capturing uncaptured values - A Danish case study on municipal preparation for reuse and recycling of waste. Resources, Conservation and Recycling, 136, 297-305. DOI: 10.1016/j.resconrec.2018.04.031.

Zajko, K., \& Hojnik, B. (2014). Key factors of starting up and developing reuse centres. Business and Management Dynamics, 4(6), 14-25. 